\title{
Early stent thrombosis. Aetiology, treatment, and prognosis
}

\author{
Paweł Tyczyński ${ }^{1}$, Maciej A. Karcz ${ }^{1}$, Łukasz Kalińczuk ${ }^{2}$, Aneta Fronczak ${ }^{1}$, Adam Witkowski ${ }^{1}$ \\ ${ }^{1}$ Department of Interventional Cardiology and Angiology, Institute of Cardiology, Warsaw, Poland \\ ${ }^{2}$ Department of Coronary Artery Disease and Structural Heart Diseases, Institute of Cardiology, Warsaw, Poland
}

Postep Kardiol Inter 2014; 10, 4 (38): 221-225

DOI: $10.5114 /$ pwki.2014.46761

Stent thrombosis (ST) is an uncommon but life-threatening complication after percutaneous coronary intervention $(\mathrm{PCl})$, frequently manifesting as acute coronary syndrome (ACS) or even cardiac death.

According to the academic research consortium (ARC), the definition includes definite, probable, or possible ST and is described in detail elsewhere [1].

Traditional classification categorises this complication into early (including acute and subacute ST, within $24 \mathrm{~h}$ and from $24 \mathrm{~h}$ to 30 days, respectively), late (from 30 days to 1 year), and very late (after 1 year). However, this classification does not include intraprocedural coronary thrombosis, which occurs in nearly $1 \%$ of patients [2] and is more common in the setting of ACS [3].

The majority of these events seem to occur within the first month after $\mathrm{PCl}$. Among 21,009 patients treated with bare metal stents or drug eluting stents (DES) from the Dutch Stent Thrombosis Registry, 437 patients experienced ST and only $27 \%$ occurred late or very late [4]. Similar results were observed with bioresorbable vessel scaffolding (BVS) within large multicentre GOUST-EU registry (1189 patients included), where ST mostly clustered within 30 days [5]. A shift toward later ST occurrence was observed within the Japanese ST RESTART registry. This included patients treated with sirolimus eluting stents and comprised 611 patients with definite ST. Among them $47 \%$ occurred after 1 year [6]. The higher rate of late and very late ST in the Japanese registry may be associated with prolonged healing of the vessel after implantation of DES with potent antiproliferative sirolimus drug.

Finally, a completely different pattern of ST timing was observed within the impressive number of 401,662 ACS patients from the CathPCI registry [7]. Among them, definite ST events were identified in 7315 . Very late ST constituted as much as $61 \%$, and only $19 \%$ of patients presented as early ST.
The broad spectrum of risk factor categories is related to the patient (incl. clinical presentation), lesion, stent, and antiplatelet therapy (Table I). Among them, premature cessation of dual antiplatelet therapy (DAPT) seems to be the strongest single risk factor for ST. However, this seems only partially true for early ST, as the majority of patients experiencing ST within the first month remain on DAPT (88\% in the Dutch ST Registry) [4]. Furthermore, as shown in the ST-elevation myocardial infarction (STEMI) patient population from the HORIZONS-AMI study, there are differences between ST risk factors for acute, subacute, late, and very late ST [8]. Acute ST was more common in ulcerated lesions and in coronaries with impaired flow at baseline (TIMI 0/1), in younger patients, in patients randomised to bivalirudin rather than unfractionated heparin (UFH) plus glycoprotein IIb/IIla inhibitors (GPI), and in those not receiving pre-randomisation UFH. The multivariable predictors of subacute ST included insulin-treated diabetes mellitus, history of congestive heart failure, baseline platelet count, baseline and final TIMI 0/1 flow, and non-use of a loading dose of clopidogrel $(600 \mathrm{mg})$. Finally, cigarette smoking and prior ACS were the only independent predictors of late ST, whereas insulin-treated diabetes mellitus, prior $\mathrm{PCl}$, baseline platelet count, and use of UFH plus GPI rather than bivalirudin were the only predictors of very late ST.

Resistance to antiplatelet therapy as a cause for ST is controversial. In a case-controlled, multicentre study, three genes (CYP2C19, ABCB1, and ITGB3) and two clopidogrel-related factors (loading dose and proton pump inhibitors) were identified to be independently associated with early stent thrombosis [9]. However, recently published European Society of Cardiology guidelines on myocardial revascularisation recommend platelet function testing or genetic testing only in specific high-risk situations. These include history of stent thrombosis, suspicion of drug resistance, compliance issue or high

\section{Corresponding author:}

Paweł Tyczyński MD, PhD, Department of Interventional Cardiology and Angiology, Institute of Cardiology, 42 Alpejska St, 04-628 Warsaw, Poland, phone: +48 696091 079, e-mail: medykpol@wp.pl

Received: 11.10 .2014 , accepted: 4.11.2014. 
Table I. Potential risk factors for early stent thrombosis from the Dutch Stent Thrombosis Registry

\begin{tabular}{lc} 
Risk factors for early ST & Odds ratio \\
\hline Premature clopidogrel discontinuation & 36.5 \\
\hline Stent under-sizing & 13.4 \\
\hline Coronary dissection & 6.1 \\
\hline Postprocedural TIMI flow & 5.2 \\
\hline$\geq 50 \%$ lesion proximal to the culprit lesion & 4.1 \\
\hline Malignancy & 3.0 \\
\hline No aspirin at PCl & 2.8 \\
\hline Impaired left ventricle ejection fraction $(<30 \%)$ & 2.7
\end{tabular}

bleeding risk (class of recommendation $\mathrm{Ilb}$, level of evidence C) [10].

Other lesion/stent-related risk factors for this complication have also been identified, such as bifurcation treatment, stent length, etc.

Several trials have reported ca. $50 \%$ reduction of ST with new-generation DES, compared to first generation DES [11]. However, this difference was primarily driven by a significant risk reduction in terms of very late ST, and not early ST.

As the first-generation DES has become practically out of use, the question of the safest profile among second-generation DES is much more intriguing.

Data from a meta-analysis [12] including 85,490 patients suggest that biolimus-eluting stents covered with bioresorbable polymer were characterised by higher rates of 1-year and long-term definite ST, compared to cobalt-chromium everolimus-eluting stents with durable polymer. As stated before [11], this study confirmed the highest risk for very late ST for paclitaxel- and sirolimus-eluting stents.

Thrombosis with the use of bioresorbable vessel scaffoldings. The single centre real-world prospective registry included 135 patients [13]. As much as 3\% of ST were observed within 6 months. Further, higher incidence of ST was also observed in the European multicentre GOUSTEU registry [5]. A total of 1189 patients were included, and the cumulative 6-month ST was $2.1 \%$. Finally, among STEMI patients from the prospective RAI registry, treated with BVS implantation, the 6-month ST rate was as high as $2.7 \%$ [14]. On the other hand, the group of ACS patients from another registry also experienced relatively high rate of ST at 1 month (2.0\%). However, this was comparable to the control DES group (1.9\%) [15]. The worrying results from these registries exceeds the ST incidence typically reported in contemporary all-comers registries of second-generation DES. Some authors suggest that, in contrast to the current recommendations for the 6-month DAPT after elective PCI with DES, in cases of BVS 12-month DAPT should be considered [13]. On the other hand, the group of ACS patients from single-centre registry also experienced the relatively high rate of ST at 1 month (2.0\%). However, this was comparable to the control DES group (1.9\%) [15].

Only a small percentage of STs present as a benign event. In the Japanese RESTART registry as many as $89 \%$ of STs presented as ASC [16]. Among the American ST patients from the CathPCl registry, ca $60 \%$ presented with STEMI, $23 \%$ with non-STEMI, and $17 \%$ with unstable angina [17].

Primary $\mathrm{PCl}$ is the treatment of choice. Despite a lack of convincing proof, the use of thromboaspiration and IIb/IIla platelet inhibitors are frequently advocated.

Aggressive post-dilatation with high-pressure balloons seems reasonable to correct stent underexpansion and malapposition. Intravascular imaging tools like optical coherence tomography or intravascular ultrasonography (IVUS) may be of value to guide coronary re-intervention

Both the short- and long-term outcomes are unfavourable; however, some differences were observed. Shortterm outcome: in-hospital mortality from the CathPCI registry was significantly higher in early ST (7.9\%) compared with late $(3.8 \%)$ and very late thrombotic event (3.6\%) [17]. The 1-year mortality rate from the RESTART registry was significantly lower in patients with very late ST $(10.5 \%)$ compared with those with early $(22.4 \%)$ or late occurrence of this event (23.5\%) [16]. Long-term outcome: some studies indicate that long-term outcome may be worse after ST within 1 year compared to very late ST. In a study by Kubo et al., which included 152 ST patients, five-year follow-up was reported. Significantly lower cumulative incidence of MACE and all-cause mortality and recurrent ST were observed after very late ST than in early ST and late ST groups. Additionally, significantly lower target lesion revascularisation rate was seen in the very late ST group. However, no statistical difference was seen for cardiac death between these groups [6].

The incidence of recurrent ST is not negligible. Based on the Dutch stent thrombosis registry, recurrent ST is time-dependant. The cumulative incidence of definite or probable recurrent stent thrombosis from this registry was $11.6 \%$ during hospitalisation, $14.4 \%$ at 1 month, $18.2 \%$ at 1 year, $19.6 \%$ at 2 years, and $20.1 \%$ at 3 years [18]. Patients with subacute ST may be more prone to develop second ST than those with acute ST [19].

The case below illustrates the possible procedural factors that can be associated with this complication.

A 60-year-old male patient with a history of ACS and $\mathrm{PCl}$ of diagonal branch in 1994 was admitted for control angiography due to recurrent angina CCS class III and positive exercise treadmill test (ETT), with ST-segment depression in II, II, aVF, V5, and V6 leads and chest pain. 


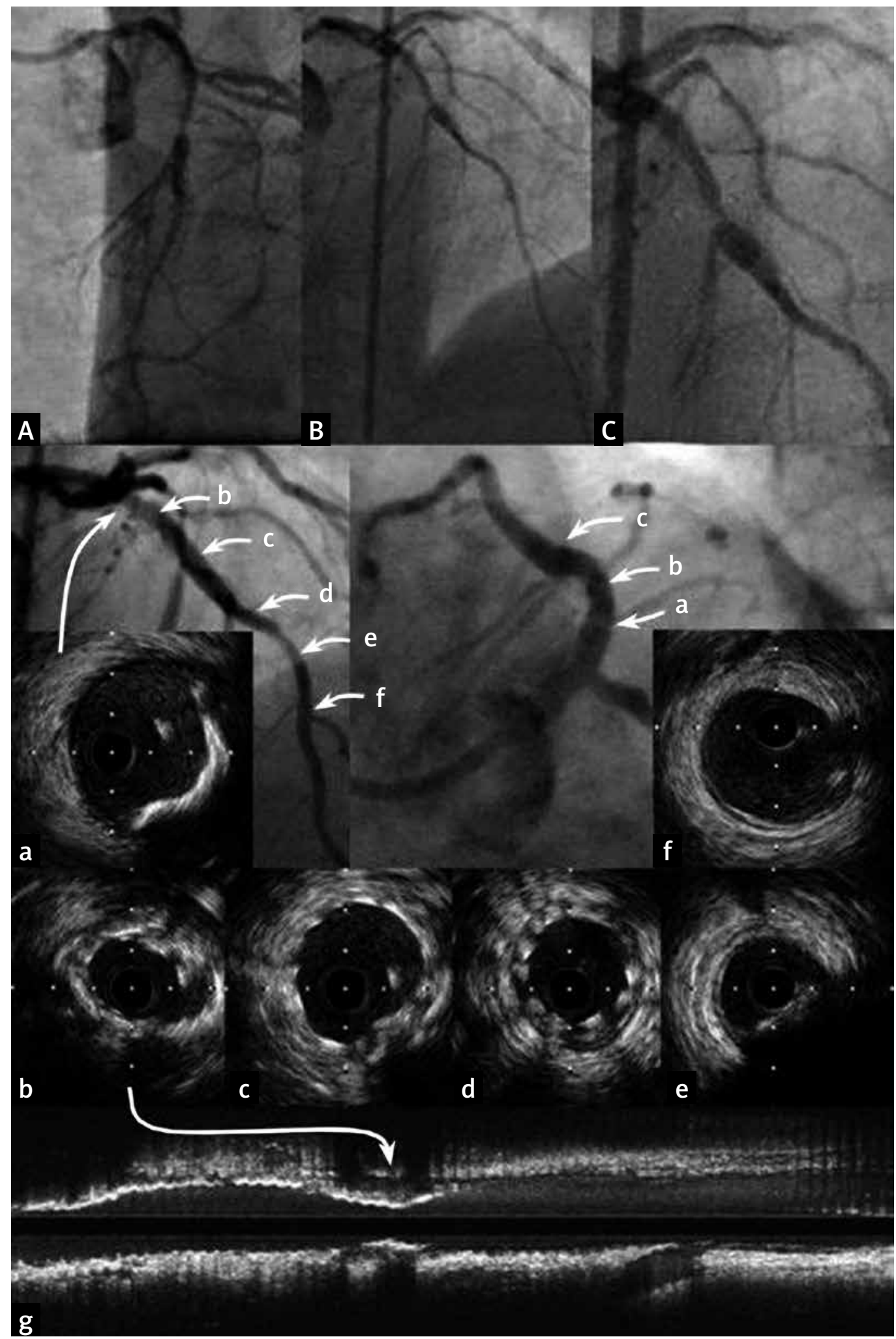

Figure 1. Images A, B - significant stenosis in proximal segment of the left anterior descending coronary artery. C - Magnification of image B. Intravascular ultrasonography cross-sections after stent implantation: a - excessive calcification, minimal lumen area (MLA) $8.0 \mathrm{~mm}^{2}$; b - ellipsoidal, underexpanded stent, MLA $3.9 \mathrm{~mm}^{2}$; c - well-expanded stent, MLA $7.9 \mathrm{~mm}^{2}$; d - malapposed struts, MLA $4.5 \mathrm{~mm}^{2}$; e - calcified, unstented lesion, MLA $3.2 \mathrm{~mm}^{2} ; \mathrm{f}$ - distal reference, MLA $7.1 \mathrm{~mm}^{2} ; \mathrm{g}$ - longitudinal view 
Occluded right coronary artery, borderline lesion in the left circumflex coronary artery, and tight lesion in the left anterior descending coronary artery (LAD) were visualised (Figures $1 \mathrm{~A}-\mathrm{C}$ ). Percutaneous treatment was chosen and accepted by the patient. Thus, IVUS-guided PCI was performed. Pre-interventional IVUS showed calcified, annular lesion in proximal LAD with minimal lumen area (MLA) of $1.7 \mathrm{~mm}^{2}$. After predilatation with a non-compliant balloon, two biolimus eluting stents $(3.5 \times 19 \mathrm{~mm}$ and $2.5 \times 18 \mathrm{~mm}$ ) were implanted. Despite post-dilation with non-compliant $3.5 \mathrm{~mm}$ balloon at $16 \mathrm{~atm}$, the proximal stent edge remained elliptical in shape and underexpanded, with MLA $3.9 \mathrm{~mm}^{2}$ (as compared to reference stent lumen of $7.9 \mathrm{~mm}^{2}$ ) (Figures $1 \mathrm{~b}$ and c, respectively). The lesion was left without further post-dilatations due to extensive, annular calcifications. Spot stent strut malapposition was visualised in distal stented segment (Figure $1 \mathrm{~d}$ ).

Three days later the patient was re-admitted with STEMI. Urgent angiography revealed totally occluded LAD in the proximal segment due to ST. Several attempts to restore reflow using non-compliant balloons (NC Quantum Apex $3.5 \mathrm{~mm}$ ) were done, but no more than TIMI I flow was achieved. Thus, manual thrombectomy was performed with removal of thrombi. Next, a biolimus eluting stent $2.5 \times 14 \mathrm{~mm}$ at $16 \mathrm{~atm}$ was implanted distally to previously implanted stents and complex post-dilatation with a non-compliant $3.5 \mathrm{~mm}$ balloon was done. TIMI III flow was then restored. Maximal Troponin T rise was $1741 \mathrm{ng} / \mathrm{l}(\mathrm{UNL}<14)$. No ECG $\mathrm{Q}$ waves were observed after the event. The patient was discharged with no angina or signs of heart failure on the fourth day post-LAD occlusion.

During repeated ETT at 5-month follow-up, $1.2 \mathrm{~mm}$ ST-segment depression in only the V 5 lead was seen at a workload of 150 Watts (100\% of predicted value for age and sex), without any chest discomfort.

Procedural factors leading to acute ST are discussed above and include stent underexpansion and malapposition (especially proximal in location), smaller stent diameter, and coronary dissection [20, 21]. Adequate preparation of calcified lesion before stent deployment is critical for good stent expansion. Interventional options to break annular calcifications and avoid stent underexpansion include rotational atherectomy and cutting balloon or hugging balloon technique [22].

Pharmacological prevention options for high-risk lesions include antiplatelet drugs more potent than clopidogrel.

Primary PCI for STEMI resulting from ST, even if successful, is associated with larger infarct territory and poorer outcome as compared to native STEMI [23]. The role of thrombectomy as an adjunctive tool for primary $\mathrm{PCl}$ after positive TAPAS trial and negative INFUSE-AMI and TASTE trials is uncertain. Surprisingly, no differences were observed in the TASTE trial subgroups, defined according to thrombus burden and coronary flow before $\mathrm{PCI}$ [24]. However, these studies were addressed to STEMI patients in native coronary arteries and not STEMI secondary to ST. Thus, the impact of thrombectomy in the ST subset of STEMI patients remains unclear. Waldo et al. observed coronary flow improvement and procedural success after use of thrombectomy in ST patients. However, this was not associated with improved long-term outcomes [25]. Conversely, in the study by Lemesle et al., the incidence of the clinical endpoint (death, recurrent MI, and recurrent ST) at 30 days was significantly lower in the thrombectomy group [26]. Similar results were observed in a retrospective study by Mahmoud et al. Among 113 patients with identified ST, manual thrombus aspiration was used in 51 patients. The use of manual thrombectomy was associated with greater epicardial and microvascular myocardial reperfusion. Additionally, mortality was lower in patients treated with thrombus aspiration, although it was not statistically significant [27].

In our case, complete flow restoration was possible only after several passages of thrombectomy. New stent implantation should be avoided unless there is a clear indication such as a flow-limiting dissection or significant lesion, left before without-stent coverage. As observed in the multicentre Spanish ESTROFA registry, implantation of a new stent was associated with five-fold increased risk of ST recurrence [28]. Increased risk of recurrent ST after new stent was also observed in the OPTIMIST study [29].

Single reports of successful systematic fibrinolysis included subacute or late ST and not acute ST [30]. A small series of subacute ST cases showed that systematic thrombolytic therapy may be very effective [31]. In some acute ST cases this treatment may also be the initial option.

Finally, as the patients with ST constitute the group of increased risk of ST recurrence, alternative regimens with more potent antiplatelet drugs may be considered. However, no trials, such as switching to prasugrel or ticagrelor or higher-dose clopidogrel, have been performed in this particular group. Some authors suggest that the benefit from the use of new antiplatelet therapy or prolongation of DAPT over 1 year outweighs the increase in risk of bleeding in most of these patients.

\section{References}

1. Cutlip DE, Windecker S, Mehran R, et al. Academic Research Consortium Clinical end points in coronary stent trials: a case for standardized definitions. Circulation 2007; 115: 2344.

2. Généreux P, Stone GW, Harrington RA, et al. CHAMPION PHOENIX Investigators. Impact of intraprocedural stent thrombosis during percutaneous coronary intervention: insights from the CHAMPION PHOENIX Trial (Clinical Trial Comparing Cangrelor to Clopidogrel Standard of Care Therapy in Subjects Who Require Percutaneous Coronary Intervention). J Am Coll Cardiol 2014; 63: 619-29. 
3. Xu Y, Qu X, Fang W, Chen H. Prevalence, correlation and clinical outcome of intra-procedural stent thrombosis in patients undergoing primary percutaneous coronary intervention for acute coronary syndrome. J Interv Cardiol 2013; 26: 215-20.

4. van Werkum JW, Heestermans AA, Zomer AC, et al. Predictors of coronary stent thrombosis: the Dutch Stent Thrombosis Registry. J Am Coll Cardiol 2009; 53: 1399-409.

5. Capodanno D, Gori T, Nef H, et al. Percutaneous coronary intervention with everolimus-eluting bioresorbable vessel scaffolds in routine clinical practice: early and midterm outcomes from the European multicentre GHOST-EU registry. Eurolntervention 2014 Jul 18. pii: 20140707-06.

6. Kubo S, Kadota K, Ichinohe T, et al. Comparison of long-term outcome after percutaneous coronary intervention for stent thrombosis between early, late, and very late stent thrombosis. Circ J 2014; 78: 101-9.

7. Armstrong EJ, Feldman DN, Wang TY, et al. Clinical presentation, management, and outcomes of angiographically documented early, late, and very late stent thrombosis. JACC Cardiovasc Interv 2012; 5: 131-40.

8. Dangas GD, Caixeta A, Mehran R, et al.; Harmonizing Outcomes With Revascularization and Stents in Acute Myocardial Infarction (HORIZONS-AMI) Trial Investigators. Frequency and predictors of stent thrombosis after percutaneous coronary intervention in acute myocardial infarction. Circulation 2011; 123: 1745-56.

9. Cayla G, Hulot JS, O'Connor SA, et al. Clinical, angiographic, and genetic factors associated with early coronary stent thrombosis. JAMA 2011; 306: 1765-74.

10. Windecker S, Kolh P, Alfonso F, et al. 2014 ESC/EACTS Guidelines on myocardial revascularization: The Task Force on Myocardial Revascularization of the European Society of Cardiology (ESC) and the European Association for Cardio-Thoracic Surgery (EACTS) Developed with the special contribution of the European Association of Percutaneous Cardiovascular Interventions (EAPCI). Eur Heart J 2014 [Epub ahead of print].

11. Stefanini GG, Byrne RA, Serruys PW, et al. Biodegradable polymer drug-eluting stents reduce the risk of stent thrombosis at 4 years in patients undergoing percutaneous coronary intervention: a pooled analysis of individual patient data from the ISAR-TEST 3, ISAR-TEST 4, and LEADERS randomized trials. Eur Heart J 2012; 33: 1214-22.

12. Palmerini T, Biondi-Zoccai G, Della Riva D, et al. Clinical outcomes with bioabsorbable polymer- versus durable polymerbased drug-eluting and bare-metal stents: evidence from a comprehensive network meta-analysis. J Am Coll Cardiol 2014; 63: 299-307.

13. Kraak R, Hassell M, Grundeken $M$, et al. Initial experience and clinical evaluation of the Absorb bioresorbable vascular scaffold (BVS) in real-world practise: the AMC Single Centre Real World PCU Registry. Eurolntervention 2014 Aug 20. pii: 20140316-04.

14. Ielasi A, Cortese B, Varricchio A, et al. Immediate and midterm outcomes following primary $\mathrm{PCl}$ with bioresorbable vascular scaffold implantation in patients with ST-segment myocardial infarction: insights from the multicentre "Registro ABSORB Italiano" (RAI registry). Eurolntervention 2014; ahead of print.

15. Gori T, Schulz E, Hink U, et al. Early outcome after implantation of Absorb bioresorbable drug eluting scaffoldings in patients with acute coronary syndromes. Eurolntervention 2014; 9: 1036-41.

16. Kimura T1, Morimoto T, Kozuma K, et al.; RESTART Investigators. Comparisons of baseline demographics, clinical presentation, and long-term outcome among patients with early, late, and very late stent thrombosis of sirolimus-eluting stents: observations from the Registry of Stent Thrombosis for Review and Reevaluation (RESTART). Circulation 2010; 122: 52-61.

17. Armstrong EJ, Feldman DN, Wang TY, et al. Clinical presentation, management, and outcomes of angiographically documented early, late, and very late stent thrombosis. JACC Cardiovasc Interv 2012; 5: 131-40.

18. van Werkum JW, Heestermans AA, de Korte Fl, et al. Long-term clinical outcome after a first angiographically confirmed coronary stent thrombosis: an analysis of 431 cases. Circulation 2009; 119: 828-34.

19. Heestermans AA, van Werkum JW, Zwart B, et al. Acute and subacute stent thrombosis after primary percutaneous coronary intervention for ST-segment elevation myocardial infarction: incidence, predictors and clinical outcome. J Thromb Haemost 2010; 8: 2385-93.

20. Alfonso F, Suárez A, Angiolillo DJ. Findings of intravascular ultrasound during acute stent thrombosis. Heart 2004; 90: 1455-9.

21. Fujii K, Carlier SG, Mintz GS, et al. Stent underexpansion and residual reference segment stenosis are related to stent thrombosis after sirolimus-eluting stent implantation: an intravascular ultrasound study. J Am Coll Cardiol 2005; 45: 995-8.

22. Ahn MS, Yoon J, Lee JW, et al. Effectiveness of the hugging balloon technique in coronary angioplasty for a heavy, encircling, calcified coronary lesion. Korean Circ J 2009; 39: 499-501.

23. Parodi G, Memisha G, Bellandi B, et al. Effectiveness of primary percutaneous coronary interventions for stent thrombosis. Am J Cardiol 2009; 103: 913-6.

24. Fröbert O, Lagerqvist B, Olivecrona GK, et al. Thrombus aspiration during ST-segment elevation myocardial infarction. N Engl J Med 2013; 369: 1587-97.

25. Waldo SW, Armstrong EJ, Yeo KK, et al. Procedural success and long-term outcomes of aspiration thrombectomy for the treatment of stent thrombosis. Catheter Cardiovasc Interv 2013; 82: 1048-53.

26. Lemesle G, de Labriolle A, Bonello L, et al. Impact of thrombus aspiration use for the treatment of stent thrombosis on early patient outcomes. J Invasive Cardiol 2009; 21: 210-4.

27. Mahmoud KD, Vlaar PJ, van den Heuvel AF, et al. Usefulness of thrombus aspiration for the treatment of coronary stent thrombosis. Am J Cardiol 2011; 108: 1721-7.

28. de la Torre-Hernández JM, Alfonso F, Hernández F, et al.; ESTROFA Study Group. Drug-eluting stent thrombosis: results from the multicenter Spanish registry ESTROFA (Estudio ESpañol sobre TROmbosis de stents FArmacoactivos). J Am Coll Cardiol 2008; 51: 986-90.

29. Burzotta F, Parma A, Pristipino C, et al. Angiographic and clinical outcome of invasively managed patients with thrombosed coronary bare metal or drug-eluting stents: the OPTIMIST study. Eur Heart J 2008; 29: 3011-21.

30. Sciahbasi A, Patrizi R, Madonna M, et al. Successful thrombolysis in patients with subacute and late stent thrombosis. Can J Cardiol 2009; 25: e213-4.

31. Koduganti SC, Shankar SJ. Systemic thrombolytic therapy for early coronary stent thrombosis: an observational study. Indian Heart J 2006; 58: 245-8. 